\title{
Toxic communication as a risk factor when promoting Health, Safety \& Environmental culture in an organization
}

\author{
Elena Pavlova ${ }^{1, *}$, Elena Terentyeva ${ }^{2}$, and Armine Matevosyan ${ }^{3}$ \\ ${ }^{1}$ Peoples' Friendship University of Russia (RUDN University), Faculty of Ecology, 6 Miklukho- \\ Maklaya Street, Moscow, 117198, Russian Federation \\ ${ }^{2}$ Volgograd State University, 100 University Avenue, Volgograd, 400062, Russian Federation \\ ${ }^{3}$ Yerevan State University, 1 Alek Manukyan Street, Yerevan, 0025, Armenia
}

\begin{abstract}
The study focuses on the problem of toxic communication as one of the risk factors in Health, Safety \& Environmental culture development. The data obtained indicate that the effectiveness of Health, Safety \& Environmental communication is reduced due to the expansion of toxic communication, which includes such phenomena as intentional confusion, topic overdiscussing, lack of dialogue on equal footing, lack of feedback, and weak corporate culture. It is also shown that in most cases, ineffective Health, Safety \& Environmental leadership of managers and chiefs demonstrates the communicative behaviour of a toxic boss. The conclusion is drawn on the need for further studies of toxic communication in order to reduce its negative impact on Health, Safety \& Environmental culture promotion.
\end{abstract}

\section{Introduction}

As a brief overview of the websites of leading Russian companies and their several subsidiaries in Armenia shows, all of them have set ambitious goals to become leaders not only in the field of production, but also in the field of industrial safety, proclaiming a firm commitment to the values of Health, Safety \& Environmental (HSE) culture. As an illustration, here are some fragments of texts posted on the official websites of the companies:

LUKOIL: HSE Management System. The 2019 results of the latest in a series of recertification audits of LUKOIL and 43 LUKOIL Group organizations confirm compliance of the HSE Management System with ISO 14001 (Environmental management system) and OHSAS 18001 (Occupational health and safety management systems).

SIBUR: Holding views the health and well-being of its personnel and all stakeholders as its top priority, emphasizing it above operating achievements. Some of our production sites fall into the category of hazardous industrial facilities, therefore ensuring safety is a major focus. The Company considers the corporate health and safety management system (HSMS) an essential component of efficient operations control, and undertakes to

\footnotetext{
*Corresponding author: pavlova-eb@ rudn.ru
} 
manage production risks that may affect employees' health and safety or facilities' property and equipment.

Rosneft: HSE IMS has been successfully operating in the Company since 2006. The Company continuously confirms the system's compliance with the requirements of ISO 14001 and OHSAS 18001 standards through certification, oversight and re-certification audits conducted by the international certification bodies.

Nornickel Group: The Company's environmental priorities include: switching the environmental management system (EMS) to a risk-oriented approach to environmental management in compliance with ISO 14001:2015.

Gazprom: The Environmental Management System (EMS) is the mainstay of Gazprom's Environmental Policy (the fundamental document regulating the Company's environmental activities). Gazprom's EMS encompasses various management levels ranging from the Company's Board of Directors to subsidiary headquarters and facilities. The EMS is deployed at 34 of Gazprom's subsidiaries specialized in exploration, production, transmission, storage and processing of gas and gas condensate, as well as investment activities.

CJSC Gazprom Armenia is a wholly owned subsidiary of PJSC Gazprom. The main activity of the company is the supply and sale of natural gas in the domestic market of the Republic of Armenia

Of course, the complete minimization of any environmental impact and the reduction of injuries and industrial accidents to zero are still difficult to achieve, but nevertheless, the development of HSE culture in an organization is the main means to pursue these goals within the framework of promotion the philosophy of sustainable production [1] and sustainable organization [2]. Therefore, the concept of HSE culture continues to be relevant. It is known that there is "an innovative approach to accelerating HSE culture in an organization based on the concept that managers, particularly senior managers, through their influence on employees, can strongly affect the HSE performance and HSE culture of an organization. For this influence to be beneficial to the organization, managers need to consistently demonstrate behaviors and characteristics of strong HSE leadership" [3]. However, both in Russia and Armenia, the development of HSE culture is accompanied by a number of difficulties of a psychological [4] and organizational and communicative nature. On the one hand, employees doubt the sincerity of managers' desire of to take care of staff and the environment, they do not believe in the effectiveness of feedback from management, sometimes neglect the requirements of safety and labor protection, demonstrate resistance to these requirements and do not report the violations to the management and relevant services. On the other hand, employees face frequent manifestations of toxic communication on the part of management, which becomes an obstacle to the development of HSE culture and a breeding ground for maintaining the negative behaviors mentioned above.

Here, toxic production communication is referred to as destructive communication in workplaces which violate ethical standards, provoke a sense of dissatisfaction and anxiety in employees, and reduce motivation for work. Toxic production communication from bosses, managers, and colleagues may cause adverse health effects in staff due to high levels of stress. Research in the field of social neuroscience showed that participants who were exposed to the threat showed a consistent increase in cortisol levels, indicative of a stress response, compared to those who did not receive a threat. These findings suggest that groupbased threats do indeed incur a stress-related physiological response [5].

The relevance of the work undertaken and the importance to study communication in an organization is explained by the fact that "communications are often a component of other HSE processes, but can exist as an HSE tool in its own right" [6]. 
The objectives of the study are to generalize the communicative aspects of the HSE culture development and promotion; to analyze the attributes of toxic communication and to identify trends which can be an obstacle to enhancing HSE culture in an organization.

\section{Research materials and methods}

The study was conducted in three stages. At the first stage, analytical work was carried out to identify the communicative aspects of HSE culture, and the attributes of toxic communication in Russian linguistic culture were specified. At the second stage, 50 employees of a large company's regional branch and 50 employees of a small enterprise were anonymously surveyed on awareness of HSE culture. Those employees who were aware of HSE culture were offered a questionnaire consisting of questions designed considering the principles of HSE culture and factors which impede its promotion. Several questions were aimed at establishing the quality of HSE communication and the presence of the toxic communication attributes. Those employees who were not aware of HSE culture answered the questionnaire about the type of communication in their organization and how it could be evaluated. At the third stage of the study, the questionnaires were analyzed, and conclusions were drawn.

Based on the analysis of the documents developed by the Institute for an Industrial Safety Culture (ICSI), HSE communication tools (Tool-box talks; HSE meetings; HSE alerts; HSE newsletters; Handover information) were established and the principles of Leadership in Safety (A guide to selecting appropriate tools to improve HSE culture; Safety leadership principles; Safety Culture), first of all, Principle 3 Share the Safety Vision: influence, persuade and promote the flow of information through the hierarchy and Principle $6 \mathrm{Be}$ available on-site to observe, listen and communicate effectively were analysed [7]. The following attributes of toxic communication at work were identified: intentional confusion, topic overdiscussing, lack of dialogue on equal footing, lack of feedback, and weak corporate culture [8].

At the second stage of the study, all respondents were asked two main questions:

- Are you familiar with HSE culture?

- Do you know what HSE communication is?

If respondents showed awareness of these questions, they further answered the following questions:

- Do you understand the gist of HSE culture?

- Do you share the values of HSE culture?

- Does your organization give HSE the same importance as issues of production and quality?

- Has HSE culture been established in your organization?

- What prevents, in your opinion, the promotion of HSE culture in your organization?

- Do you have an opportunity to make suggestions for improving HSE culture?

- Do you report safety requirements breaches?

- Does the management respond to suggestions and complaints regarding safety in your organization?

- Does your organization analyse industrial accidents?

- Are HSE issues regularly discussed with employees?

- Do all meetings begin with HSE information (Safety Moment)?

- Do you feel annoyed when there is no clear HSE communication?

- Are HSE issues discussed with employees in an informal setting?

- Can HSE communication be considered effective in your organization?

- What prevents, in your opinion, the effectiveness of HSE communication in your organization? 
If the respondents were not aware of the HSE culture and HSE communication, they were asked questions regarding the specifics of production communication and its organization.

The survey showed that the staff of a large company (78\% of respondents) was more informed about HSE culture. The employees of a small organization were almost not familiar with HSE culture. The questionnaire results were processed using the Analysis ToolPak in Excel.

\section{Results}

Those questionnaires were especially thoroughly analysed in which respondents noted the presence of ineffective HSE communication or noted such communication features that we qualified it as toxic. The respondents' answers were summarized, and the table below shows the results:

Table 3. Types of communication based on the survey results.

\begin{tabular}{|c|c|}
\hline $\begin{array}{c}\text { Type of } \\
\text { communication }\end{array}$ & Examples \\
\hline $\begin{array}{l}\text { Ineffective HSE } \\
\text { communication }\end{array}$ & $\begin{array}{c}\text { The requirements are not clear. } \\
\text { General words are told about honesty, trust, commitment and care. } \\
\text { HSE communication exists only on paper. } \\
\text { The management keeps giving the same thing over and over again at } \\
\text { meetings. } \\
\text { No feedback. } \\
\text { They often use words and abbreviations I don't understand. } \\
\text { My boss only demands. }\end{array}$ \\
\hline Toxic communication & $\begin{array}{c}\text { Opposite and confusing orders are usually made. } \\
\text { Long and pointless meetings. } \\
\text { Abusive relationship with subordinates. } \\
\text { Lack of feedback. } \\
\text { Lack of corporate culture. } \\
\text { Fear of the boss and fear of expressing my point of view. } \\
\text { Surveillance and denunciations by managers and heads of services. }\end{array}$ \\
\hline
\end{tabular}

As can be seen from the table, ineffective HSE communication is very close to toxic communication. Where there is a formal approach and incomprehensible terminology is used, no personal interest of the leadership, no positive emotional impulse from a safety leader to promote HSE culture values and no constant open dialogue, the attributes of toxic communication are clearly manifested, which broadens the scope of its functioning. In other words, HSE communication often exists only on paper, in plans and reports, but in fact, toxic communication dominates, which negates all efforts of HSE management.

All respondents noted that ineffective communication occurred when there were "shouts and threats from the boss, conflicting orders", "no feedback", "only formal communication and no close contact and dialogue".

\section{Conclusions}

Thus, we have noticed a tendency of HSE communication to replace toxic communication. We have also noticed one more tendency, according to which the expansion of the toxic communication scope contributes to the transformation of a safety leader into a toxic boss. Of course, we understand that the study undertaken cannot be exhaustive and needs to be continued in order to reduce the negative impact of toxic communication on the HSE culture promotion since the results show that toxic communication remains a significant barrier for targeted changes to people's attitudes towards safety and for establishing constant contacts with them in order to ensure accurate feedback. 


\section{References}

1. J. Pfeffer, Academy of Management Perspectives, 1-27 (2010)

2. E.B. Pavlova, E.V. Terentyeva, IOP Conference series: MSE (2019)

3. K. Breitsprecher, J. Hinton, W. Harris, S. Crabb, P. Jacques and B. Hoedt, SPE 2 (2012)

4. A. Guslyakova, N. Guslyakova, V. Kirsanov, M. Vetkhova, L. Poluyanova, E. Sharipova and A. Bengardt, IJCIET 10, 2 (2019)

5. S. Sampasivam, K.A.Collins, C. Bielajew and R. Clément, J. of Language and Social Psychology 37, 6 (2018)

6. A guide to selecting appropriate tools to improve HSE culture. Report No. 435 (2010)

7. ICSI https://www.icsi-eu.org

8. L. Too, M. Harvey, Journal of Corporate Real Estate 14, 3 (2012) 